\title{
A Simulation-Based Model for Teaching Business English: An Application in the Tourism and Hospitality Industries
}

\author{
Dr. Andrew Szanajda ${ }^{1^{*}}$, Dr. Fang-Chun $\mathrm{Ou}^{2}$ \\ ${ }^{1,2}$ Overseas Chinese University, Taiwan
}

*Corresponding Author: Dr. Andrew Szanajda, Overseas Chinese University, Taiwan

\begin{abstract}
The purpose of this work is to present a simulation-based, authentic activity in the field of business English, as the dual goals of teaching business skills along with English communication protocols and language abilities are vital for real world success in a future workplace. This work will examine the existing literature that highlights the importance of communication in business operations, and thereby demonstrate the importance of learning through applying realistic simulations. There are various uses and applications in the classroom in a wide variety of contexts. Business-related concerns specific to the industries of tourism and hospitality are going to be examined in order to provide a sense of an appropriate scope for a practical simulation project that features authentic assessment that are to be consistent with effective education practices, as well as common practices in the hospitality industry in particular. The simulation outlined in this work can thus prepare students to function in business environments, whether at home or abroad in any language.
\end{abstract}

Keywords: Business English, Simulations-Based Model, Tourism and Hospitality Industries.

\section{INTRODUCTION}

Being able to communicate effectively in English has remained being increasingly important in various contemporary business environments. While these environments can generally become increasingly global in nature in terms of involving people from around the world, English has remained being the worldwide lingua franca, and therefore being bilingual is certainly an asset, while being fluent in English is often a compulsory condition for most positions, as is the ability to communicate in various forms of media. Yet, being able to operate in English is insufficient to prepare students for real world applications in the workforce. They must also be able to perform various tasks, and these include far more than simple face to face communications. This is especially case in the tourism and hospitality industries, where a great deal of the workload commonly involves communication with others, often over wide distances, and also taking different cultures of the people involved into account in order to help allay the potential of there being misunderstandings. Hence, with all of these myriad factors, the question becomes how instructors can effectively train students who intend to enter the tourism and hospitality industries and are learning English as a second language. Straightforward English language instruction, even if it is of high quality, is insufficient as a means of being prepared for these types of workplaces. This likewise applies to the instruction for students who are learning about these industries and learning English as well. A potential solution lies in setting up classroom activity simulations that will provide students with a combination of opportunities to communicate and to learn business-oriented skills as well in conjunction with simulation-based tasks that allow for authentic assessment and having students collaborate, just as they would in the real world. These are the key elements to effective instruction in this field of study. This work will thus present a simulation-based, authentic activity to be staged in an ESL business classroom, as the dual goals of teaching business skills along with English communication protocols and language abilities are vital for real world success in a future workplace.

\subsection{Literature Review}

In order to determine what roles simulations can play in this particular field of business education in English, it is important to identify various current strands of thought within the scholarly community concerning practices relating to education, business, and the specific industries in question. This literature review will examine the importance of communication in business operations, with a 
specific focus on speakers of English as a second language and English as the language of business communication. This will be followed by exposing the importance of learning through applying simulations, and its increasing number of uses and applications in the classroom in a wide variety of contexts. Finally, business-related concerns specific to the industries of tourism and hospitality are going to be examined in order to provide a sense of an appropriate scope for a practical simulation project that features authentic assessment, and is consistent with effective education practices, as well as best practices within the hospitality industry in particular.

\section{ENGLiSH AS A COMMON LANGUAGE WORLDWIDE}

While anyone with experience in the business sector might have rudimentary knowledge regarding the notion of English as the global language of communication, scholars have forwarded various views. Baker (2009) takes a theoretical approach, but confirms the notion of English as a lingua franca not just in the business community, but also for the world at large. Although he cautions that the specific dimensions of English used are heavily context-dependent, his work also demonstrates the importance of English for business communication, including through indirect means. Suarez (2005) finds that some countries have adopted using English more commonly than others. Location-specific differences are important to note in the context of individual projects and locations, but the overall consensus is clear: English is the language of the world in terms of political and economic life in the global marketplace.

Altbach (2007) confirms this with a discussion of the importance and prevalence of English as an academic language worldwide. If students intend to study at top universities and attend noteworthy academic conferences, which could lead to acquiring improved employment opportunities in their chosen fields of study, English is definitely the language in which they must be able to communicate. Ammon (2010) believes that English has risen to its contemporary preeminent position in very many fields due in part to the simultaneous decline of other previously important world languages as tools for international communication. While he notes the importance of learning other languages apart from English, it is to be recognized that English is the most important language to know, which thereby places an advantage into the hands of business students who speak another language.

\subsection{The Importance of English Communication in Business}

Communicating in English fluently is increasingly more crucial for those who intend to succeed in the business world. In many industries, engaging non-native speakers who are fluent in English is already the common standard. For example, Raina \&Pande (2012) found that Indian engineers in the information technology sector were especially skilled in listening in English, and were able to apply their listening skills to respond with flexibility and make spontaneous adjustments during decision making. These oral language skills consequently set them up for professional success.

In view of the importance of knowing English in a variety of businesses, many franchised companies that have expanded on an international scale, such as chain restaurants, demand a certain level of English proficiency for potential employees, as reported by Yaffe\& Rosario (2009). One of the reasons is allowing for training and professional development to be standardized and streamlined. This is a reasonable expectation in the financial sense, since training and issuing regulations and conducting workplace functions can be streamlined and supervised more easily in one language rather than multiple ones. This is another way that English communication is important for business success

Within English as a business language, there are shades of meaning and of practice that must be addressed. Zhu (2009) introduces the concept of semantic frameworks, which she defines as there being culture-specific interpretations of meanings. Her study compares managers in China and in New Zealand, which indicates that they prefer and gravitate toward different semantic frameworks that correlate to one's culture and nationality. Everything from the language used to the type of communication strategy that is applied to initiate a business relationship has a cultural dimension. According to Grosse (2004), the vast majority of those who have experience functioning in an international management program and were native English speakers expressed that a program's requirement extending for four semesters of studying a foreign language and having a foreign cultural education had been greatly helpful to them in their careers. Learning about semantic and cultural dimensions was cited as the most helpful contents that set them up for success on the international stage. 
These cultural elements that compose parts of business education for English speakers are a potential area of strength for students who are learning English for business from a foreign context, since they may already be familiar with the semantic frameworks that are optimal for their situations. Without this familiarity, problems can definitely ensue. Henderson (2005) wrote about linguistic diversity in international management teams from a sociolinguistic perspective, and found that there are unique challenges that result from working in managerial groups that come from different cultural and linguistic backgrounds, even when they share English as a common language. Both native and nonnative speakers in Henderson's study reported barriers that stemmed directly from these cultural and linguistic differences, and this author thereby drew the conclusion that managers require practice and education in dealing with these differences, either in their careers, or beforehand during their professional education. One way to practice these skills is through creating classroom simulations in the classroom that can help students hone their communication skills in specific contexts, and among diverse groups of others who might represent the different cultures they will encounter.

\subsection{Learning via Simulation}

Simulations are a means to teach students in an authentic manner by creating replications of real life conditions, and therefore have been increasingly recommended as learning tools in a variety of contexts. Schmidt (2003) pointed out that the technology of the World Wide Web and networked computers have made simulation-based learning a viable tool for teaching complex concepts to students of all levels. Schmidt's particular study involved teaching economics to students, and they were able to use a simulation to learn about investments and trade in a more complex, and thus more realistic manner, rather than the traditional paper and pen based simulations that had been used until that time. Schmidt's recommendations about the generally positive nature of simulation-based tasks for business learning remain being valid, and his observations about technology have become increasingly more relevant. As technology has become increasingly more advanced, simulation tasks can become increasingly more complex and there could be additional variables and factors that could come into play, just as business situations do in the real world. Simulation-based learning is therefore becoming a tool that is becoming increasingly more valuable over time.

Simulations can be applied to almost any situation. Brynen (2010) discusses the use of a simulation game type activity to help students learn about the challenges of the multinational peace process after a war. The necessary negotiation and problem solving skills are complemented by the complex scenario of the simulation given in his examples. This approach could be used in determining a path forward when there is not any specific right answer, just as this is not often the case in business situations. In other words, it is unrealistic to presume that are potential template solutions for various problems.

In fact, business students in particular can use simulations as part of their learning to acquire very positive effects. As early back as in the 1980s, Klein (1984) commented on the feasibility of using simulation-based tasks for international business students to specifically work on international concepts that they could not easily learn otherwise. Different forms of technology that are currently available make it more possible for students to learn international business through working remotely with genuine international companies, such as through working in an internship. For those who cannot gain international work experience or a real-world connection in the international sector, using a simulation can be just as effective, just as it was when Klein was undertaking his work, and it is currently very likely to be easier for an instructor to set up simulations by using the latest forms of technology, such as using newly introduced virtual reality devices.

Smutny, Prochazka, \&Vaculik (2016) formulated a simulation game that allows coworkers to assess their managerial skills and those of their colleagues. This game is an intensive, long-term simulation in which the players rotate through different roles. The participants in their study gained insight into their own strengths and weaknesses, along with those of others through fulfilling the tasks involved. Salas, Wildman, \& Piccolo (2009) also advocated the use of simulations to provide training for managerial skills. They examined learning modules that they called S.B.T. (simulation-based training) as a potential method of intervention for managers who are already in place and need to improve or acquire additional skills in the workplace, while the same concept can easily be adopted in the classroom, and particularly in an ESL classroom. According to Hwang (2001), simulations have been 
used for different subjects as classroom activities. These are often used in engineering and other technical disciplines that require students to be able to program to run simulations.

In fact, simulation is particularly uniquely suited to students learning English as a second language. Oxford (1997) discussed three different forms of communication that must be addressed specifically in a L2 (second language) classroom: cooperative learning, collaborative learning, and interaction. All of these three can be achieved by administering simulation tasks. Cooperative learning features students working together on a task, which takes place as simulations are almost always conducted as group activities. Collaborative learning involves taking the perspectives of others into account. Rather than merely dividing tasks, as might be done with cooperative learning, group members must cooperate. There is also the element of interaction, which takes place in various ways within a simulation. Group members must interact with each other during the process of completing tasks, and there is also the need to interact in the presentations that they are going to give as they present their conclusive findings. Simulation-based learning aligns with the most effective long-standing practices for teaching students of English as a second language through engaging them in tasks while having them function independently, as well as being used teaching and learning about the business practices.

Drougas \& Johnson (2004) highlighted the success of simulations, in terms of generating complex problems that cannot be solved purely by theoretical analysis, and must require trial and error attempts along with clear communication. These types of problems abound in the business world. This study specifically concerned simulations relating to financial forecasting, while their overall purpose of using simulations in the context of business decision making remains valid as a practical application. When one is trying to learn about a complex topic, particularly in a language other than one's native language, the more complex and engaging a simulation can be. This in turn challenges students and forces them to hone their communication skills, in addition to the underlying element of learning the course contents.

\section{CONCERnS Relating to THE Hospitality AND TOURISM INDUSTRIES}

When designing a simulation to function within the scope of instruction for the tourism and hospitality industry in particular, there are specific concerns and ideas that must also be examined beforehand. Doherty, Klenert, \&Mandfredi (2007) described how there are international graduates, especially Asian ones, who speak English and are prepared to enter the hospitality and tourism industries, or the restaurant sector in particular in this study. These graduates are specifically concerned about the benefits package they are going to receive, and also, as well as more importantly, about career advancement opportunities. These opportunities arise with the ability to complete different types of tasks, making decisions independently, and leading a team. Hence, any simulation that is designed for this industry should help students develop those specific skills so that the students who are going to operate in these situations will be prepared in the best possible way for their future careers.

Although cultural factors and sensitivity are important in all contexts, they are especially important in the tourism industry. Hence, a simulation activity in this field of study must include certain ways of having students deal with these factors. Tourists have many choices as to where to make purchases, both in terms of destinations on their travel itineraries along with any types of goods and services they could be interested in. In order to be successful, it is therefore especially important for professionals in these industries to be culturally sensitive, and specifically to the types of tourists that visit their workplace environment, and to whom they will be providing services and/or selling products. McGuigan (2002) noted that taking these considerations into account can be a differentiator for companies in a crowded and competitive industry.

Any simulation that is geared toward a specific industry must take into account the concerns and challenges that the students doing the simulation, considering they will work in the specific industry and are going to face specific situations. Therefore, it is important to understand the challenges of the tourism and hospitality industry as they currently stand on a wider level. Duncan (2005) notes that the environment is one of the huge challenges facing tourism, and that has only become increasingly more relevant in the years since her study highlighted this issue, as climate change is a growing concern in many tourist destinations, especially those in low lying regions, such as those found on seasides. Zeppel\& Beaumont (2012) explored some of the ways that governments are working to 
combat carbon emissions and the global warming that will cause problems for these destinations, which is likewise a current focus of the industry. In places where natural disasters, such as earthquakes and tsunamis, have struck, it is important for the industry to rebound, and it is clear that some areas can manage this better than others. Machado (2012) pointed out the importance of selling the safety of a place to visitors after there had been a disaster in the area. Another matter of concern is image recovery. In the case of cities such as New Orleans, Huang, Tseng, \&Yiap (2013) argued that these tourist destinations that were once considered fun and exciting can become less desirable when there is a great amount of publicity about crime and negative reports in general about those areas, as was the case after Hurricane Katrina, which was cited in their study. One important skill for industry leaders is therefore to be able to mitigate these types of perception damage about a specific destination.

Along with dealing with the specific challenges of marketing that climate change and natural disasters can bring, the tourism and hospitality industries are also exploring new areas of what might be called "focused" tourism, which entails finding ways to sell destinations that might not otherwise be desirable. One example is archaeological tourism. According to Diaz-Andreu (2013), this has become a growing sector in Latin America to the extent that the industry must contend with the ethical implications of potentially damaging archaeological or historical heritage sites due to the sheer volume of visitors. Irandu and Shah (2016) cite the growth of cultural heritage tourism, a related subindustry, in Kenya, where it is being used to drive diversification of tourism products that are offered. Food tourism is another example of a specific type of targeted tourism being developed in order to entice visitors to new locations. Lin, Pearson, \&Cai (2011) found that there are multiple dimensions of food that can be "sold" to tourists, and that exotic dishes are a powerful driver to turn a destination into a long-term sustainable brand in the minds of tourists. Something that a simulation must take into account in order to be effective is therefore the specific characteristics of the destination with which students will be working, while these students need the chance to research, understand, and communicate these ideas, as well as to think strategically about how to market their particular area of the world.

A final section that the simulation must take into account is being specifically useful to this industry. This entails considering the behaviour of the consumers who drive most of the market and how to market to them - leisure travelers. Envisaging how to prepare to deal with this segment is part of what the simulation will be meant to engender. Jones \& Chen (2011) examined how consumers choose accommodations, and this process can be extended to other spheres of the hospitality industry as well. Service (Wynter-Palmer, 2011) and marketing online, as examined by Essawy (2011) and in other venues (Crawford, Deale, \& Merritt, 2013) are all differentiators that could lead to having consumers choose one destination, hotel, restaurant, or activity over another, and therefore any simulation needs to address marketing to and the behaviour of leisure travelers in particular.

\subsection{A Simulation for the Hospitality and Tourism Industry: Rationale and Procedures}

Formulating the use of a simulation in the tourism and hospitality industries has previously been applied as a teaching tool. Laborda (2009) used "webquests" that were in many ways similar to the simulation proposed in this work as a course requirement in a Tourism Studies major program. There is therefore a precedent that has been set for the use of simulations specifically in this industry, and this proposed activity will draw on what has been done.

In the proposed new type of simulation, students will be placed in groups that should be intercultural, as far as this can be practicable, in order to give them practice with dealing with the issue cited in the above literature review. However, it is important for purposes of this activity that students be grouped in mixed-fluency groups as well, if there is a variation in fluency in English proficiency within the class. Students can therefore pursue the type of collaborative and cooperative learning that serves as useful practice in an ESL classroom, while also gaining content knowledge and skills in their future industry of choice. Students should therefore be formed into random groups assigned by the instructor. Within these groups, the separate members can assign and select roles and workload among themselves in order to create a situation relating to projects are done in the real-life workplace as realistically as possible. This simulation will have several components, and each of them is going to require communication in English that can be formally assessed by the instructor. 


\subsection{Destination Selection}

Each group will be given the task of drafting a tourism strategy for a destination of their choice. The first step in this process is selecting the destination, which requires research and drafting a memo document to explain the reasoning for their individual choices. Students should brainstorm a list of possible factors to consider, including potential attractions at a given destination in general, and then research two or three potential destinations. This process should be collaborative among the entire group, and individual students can be encouraged to divide these tasks and make informal presentations among themselves to evaluate the advantages and shortcomings of different destinations, before determining a potentially ideal one as a group.

This section of the simulation will involve drafting writing in memo format that outlines the research process, how the potential destinations were chosen, and the reasoning for the selection that the group had made. This memo must be submitted to the instructor, and the choice of destination must be approved before the group can continue with the next phases of this simulation. This can then all be done simultaneously, or according to a more flexible schedule.

In order to select a destination, students should take a various factors into account. Depending on the level of the class, these might be discussed as a whole class activity, or students might work on brainstorming them separately in their groups. Matters of concern could include the level of current tourism in an area, costs, and access to an area, and opportunities for special types of tourism activities. There should be evidence of these factors clearly stated in the memo, since the students are going to be responsible for researching potential destinations of their choice, before ultimately selecting their ultimate destination choice for the rest of the project. In the event that the instructor could introduce a greater element of competitiveness among higher level students, they could also be encouraged to also make arguments against other destinations and make comparisons between them.

\section{SWOT ANALYSIS}

Once the destination selected by the group has been approved by the instructor, the group can then begin working on the remaining tasks as separate parts of the simulation. The first of these is the SWOT analysis as a basic marketing document to be completed in writing for the selected destination. Each section will have to be completed with as much supporting detail as possible to answer any potential questions.

The STRENGTHS section of the analysis should focus on the positive features of a tourist destination. This could include mentioning the infrastructure that is already available for tourism, as well as the cultural, natural, or other attractions. Drafting this section will allow students to write descriptively in a way that other areas of the simulation may not. The WEAKNESSES section should address the competition that is already in the area, as well as any problems with the destination as it currently stands, such as political unrest, weather conditions, or the possibility of crime. OPPORTUNITIES should compose the largest section of the analysis, and should focus on the areas that the group considers to be currently being under-leveraged with regard to tourism. Could the area become a possible destination for specialized purposes, such as ecotourism, or for food-based tourism? Is shopping one of the local attractions? These could be examples as marketing materials that should be researched and answered in detail in this part of the analysis, and the instructor evaluating it should evaluate thorough and creative engagement with all possibilities. Finally, the THREATS section of the analysis should focus on potential future problems that could undermine the tourism strategies discussed in the previous section. These could include potential natural disasters, oversaturation of the market, with the accompanying problems of keeping natural resources intact for nature-based tourism, among other issues that might arise in the future.

In terms of the students' evaluation effort for this part of the simulation, there should be a written component in which students should work on together. The instructor could recommend using GoogleDocs or other collaborative software to edit and comment on each other's work, as this relates to a great deal of different types of communication skills necessary in the real world. Groups should also present the SWOT analysis in visual form as part of a presentation.

\section{Advertising Campaign and Branding Presentation}

The next section of the simulation will involve creating a presentation that could be given to a local tourism board of a country or city, selling the vision that the group has for that part of the world as a 
tourist destination. This should include elements of branding, such as slogans and logos, as well as the presentation for a tourism strategy for the region: how can students present this destination as it is demonstrated in the SWOT analysis? Depending on the specific interests of the class or the group, the presentation could include elements of video or internet marketing, a timeline for marketing and branding roll-out, graphic design elements, among any other considerations to be added at the discretion of the group effort. It should also include clear understanding of the market to which the destination will be sold: is it travelers with a certain interest, or from a certain region?

The presentation should take the form of a PowerPoint or other multimedia presentation, but should also include an oral component - it can be presented via video or in person to the rest of the class along with the instructor being present. This will allow for the instructor to differentiate for the learning needs of different groups, and allow for this simulation to be used repeatedly with slightly different concentrations: one group may need to be required to have all students talk as part of the presentation, while another group may need to focus more on the written component or the presentation and use of language in the context of using multimedia.

An additional element for this section of the simulation would be to simulate the presentations themselves with a panel of people representing a tourism board from the chosen destination. This would allow students to navigate among some of the cultural differences and differences in communication styles, which can be difficult to understand and prepare for in a business environment. This addition to the simulation should be attempted if a panel can be organised to be as realistic as possible. If the area being presented is in China, having someone of Chinese extraction and who is a native speaker of a Chinese regional language, such as Mandarin or Cantonese, on the panel would be useful, whereas that same panel member might not be as helpful for student learning via interaction if the selected destination is a destination in a European or South American country. The decision to include this recommended component of the simulation therefore remains being at the instructor's discretion.

\subsection{Advertising Products}

Another section of the simulation is the creation of media materials to include a brochures and posters that are aimed at the particular tourist demographics the group has decided to target. This is an area in which students can explore cultural communication styles, since the way one might target or try to entice, for example, senior citizens from European countries might be different from the way to entice American university students on spring break. The linguistic choices can include subtle differences that relate to the connotation of words, as opposed to the denotation, or meaning, as well as cultural signifiers. Even the mode of address, formal or informal, might vary depending not just on the age, affluence, class and education level of the target population, but also on where they are from and their cultural backgrounds as well.

This part of the simulation can be as extensive or limited as the instructor plans, and copies of the products themselves are the only products necessary for assessment. This is a useful area for collaboration for students whose oral fluency in English could be limited, but can nevertheless deploy their unique cultural understandings and perspectives for the benefit of their group as a whole in order to make the marketing materials represent the best possible quality in terms of marketability.

\subsection{Itineraries}

A final section of the simulation addresses the current trend within the hospitality industry for themed tourism. This part of the simulation involves creating two different itineraries that would work for two different demographics of tourists, or types of tourism. This is an opportunity for students to gain exposure into the competitive landscape of tourism in their chosen destination or area. They could potentially look at and compare various hotels and attractions in order to determine the best possible itinerary for a themed, guided trip in their chosen area and add realistic expectations and justifications. These trips can be presented as part of the advertising campaign and branding presentation section of the simulation as well, either in whole or in part, and could also be a section of the text material for the paper products part of the simulation. The instructor can modify this part of the activity to make it more or less rigorous by giving particular instructions, in terms of how many days of activities these itineraries should include, whether or not they need to be at specific price points, or set other parameters at their discretion with added input from the students' themselves. It might be an 
interesting exercise for students to create different types of itineraries for different tourist demographic entities. It is to be maintained that these activities address written communication and oral communication through interactive group collaboration, as well as engage with the important cultural literacy elements that are inherent in the success of business education with a focus on the hospitality and tourism industry.

\subsection{Potential Extensions and Modifications}

The parameters of this simulation should be left being deliberately flexible in many areas in order for instructors to create the best possible set of activities for the student groups. Groups who are more fluent in conversational English may not be required to work as collaboratively as those who need practice in this area. The instructor can create rubrics that focus on what the students specifically need in all parts of the simulation to gain different forms of competency in English communication.

The inherent flexibility in this simulation also means that it can be adapted to students at different places in their studies. Business management major students could complete this simulation as a kind of introduction to the industry of hospitality or tourism, and more advanced students would be creating products that might lead to job opportunities. This could also be ideal for applied English major students who intend to work in the hospitality and tourism industries and could require a certain degree of exposure into business practices. The instruction could according use these projects to help connect students with members of the business community who might be interested in their ideas or performance, and invite them to class presentations to provide real world feedback, or even to play the roles of the tourism board in the simulation, if that part of the activity is set up. Thus, this simulation can also be a gateway to contacts that might help students who are close to entering the business world as career seekers.

Finally, the simulation is flexible in terms of time. It could be done at the end of a semester as a final assignment, or it could be the basis of a semester-long investigation around which a marketing class, for example, is based. It might also serve as a potential independent study for schools in which that is a curricular option for students. This level of flexibility in terms of products, focus, grouping, and timing both within a semester for a students' education requirements means that the simulation outlined here can continue to be repeated and to be useful to instructors in a variety of circumstances.

\section{CONCLuSiON}

The use of simulations for teaching business writing and communication skills to students of ESL is ultimately a greatly practical tool. In the context of any industry, communication in English is enormously important, and students need to be able to compete in the increasingly saturated market of recent university graduates. As the business world has been shifting to an increasingly more international focus, there may be a wider range of opportunities available for students everywhere worldwide. In order for ESL students to highlight their knowledge and skills in a competitive job market in which they may often be competing with native speakers, it is important for them to be able to communicate in English as fluently as possible, while using the lingua franca of the business world. Communication is not limited to just speaking, and must include reading, writing, and the use of multimedia and different form of technology as well. Using simulation as a learning tool can help ensure all of these facets of communication are combined and addressed, even when students are not specifically in the ESL classroom in which they are learning language skills in a classroom setting.

In the final analysis, students who speak a language other than English are set up for unique success in the business arena because of their linguistic capabilities and cultural backgrounds, which can be assets in terms of bringing diversity to a team, and also in terms of allowing them to communicate well with people from various parts of the world. However, the key to a solid business career is good communication skills in English, and therefore these skills can best only be brought to bear if students have a solid foundation in English language skills, and as a language for business communication in particular. The simulation outlined in this work can thus prepare students to act independently in a business environment.

\section{REFERENCES}

[1] Altbach, P. (2015). The imperial tongue: English as the dominating academic language. International Higher Education, (49). doi:10.6017/ihe.2007.49.7986 
[2] Ammon, U. (2010). English and other international languages under the impact of globalization. NeuphilologischeMitteilungen,111(1), 9-28. Retrieved May 05, 2017, from http://www.jstor.org/stable/ 10.2307/ 43344446?ref=search-gateway:a46545599f1c12a951b297393a886f54

[3] Baker, W. (2009). The cultures of English as a lingua franca.TESOL Quarterly,43(4), 567-592. Retrieved May 05, 2017, from http://www.jstor.org/stable/10.2307/27785045?ref=search-gateway:e9d44dba699b462 f3f70c 93326ab5d3f

[4] Brynen, R. (2010). (Ending) civil war in the classroom: A peacebuilding simulation. PS: Political Science \& Politics,43(01), 145-149. doi:10.1017/s1049096510990719

[5] Crawford, A., Deale, C. S., \& Merritt, R. (2013). Taking the pulse of the B \& B industry: An assessment of current marketing practices. Tourism and Hospitality Research,13(3), 125-139. doi:10.1177/1467358414522054

[6] Diaz-Andreu, M. (2013).Ethics and archaeological tourism in Latin America. International Journal of Historical Archaeology, 17(2), 225-244. doi:10.1007/s10761-013-0218-1

[7] Doherty, L., Klenert, A., \&Manfredi, S. (2007). Expanding into Asia: The human resource challenge. Tourism and Hospitality Research,7(2), 109-121. doi:10.1057/palgrave.thr.6050038

[8] Drougas, A. M., \& Johnson, A. C. (2004). Use of simulation to enhance undergraduate financial forecasting education. Journal of Financial Education,30, 26-43.

[9] Duncan, T. (2005). Current issues in the global hospitality industry. Tourism and Hospitality Research,5(4), 359-366. doi:10.1057/palgrave.thr.6040034

[10] Essawy, M. (2010). Egyptian hotel marketing managers' perceptions of the Internet's impact on marketing. Tourism and Hospitality Research,11(3), 207-216. doi:10.1057/thr.2010.26

[11] Grosse, C. U. (2004). The competitive advantage of foreign languages and cultural knowledge. The Modern Language Journal,88(3), 351-373. doi:10.1111/j.0026-7902.2004.00234.x

[12] Henderson, J. K. (2005). Language diversity in international management teams. International Studies of Management and Organization,35(1), 66-82.

[13] Huang, Y., Tseng, Y., \&Yiap, L. (2013). Image recovery of the resurrected seashore city:” New Orleans, Louisiana. Journal of Coastal Research,287, 430-437. doi:10.2112/jcoastres-d-12-00100.1

[14] Hwarng, H. B. (2001). A modern simulation course for business students.Interfaces,31(3), 66-75. doi:10.1287/inte.31.3.66.9631

[15] Irandu, E., \& Shah, P. (2016). Development of cultural heritage tourism in Kenya: A strategy for diversification of tourism products. In A. Deisser\& M. Njuguna (Authors), Conservation of natural and cultural heritage in Kenya: A cross-disciplinary approach. London: UCL Press.

[16] Jones, P., \& Chen, M. (2010). Factors determining hotel selection: Online behaviour by leisure travellers. Tourism and Hospitality Research,11(1), 83-95. doi:10.1057/thr.2010.20

[17] Klein, R. D. (1984). Adding International Business to the Core Program via the Simulation Game. Journal of International Business Studies, 15(1), 151-159. doi:10.1057/palgrave.jibs.8490478

[18] Laborda, J. G. (2009). Using webquests for oral communication in English as a foreign language for Tourism Studies. Journal of Educational Technology \& Society,12(1, Knowledge Infrastructure of the future), 258-270. Retrieved May 05, 2017, from http://www.jstor.org/stable/10.2307/jeductechsoci. 12.1.258?ref=search-gateway:ffcb65bb5045b87ff192e8cdfa805fa8

[19] Lin, Y., Pearson, T. E., \&Cai, L. A. (2010). Food as a form of destination identity: A tourism destination brand perspective. Tourism and Hospitality Research,11(1), 30-48. doi:10.1057/thr.2010.22

[20] Machado, L. P. (2012). The consequences of natural disasters in touristic destinations: The case of Madeira Island $\hat{a} \square$ "Portugal. Tourism and Hospitality Research,12(1), 50-56. doi:10.1177/1467358411429636

[21] McGuigan, G. S. (2002). When in Rome: A rationale and selection of resources in international business etiquette and intercultural communication. Reference \& User Services Quarterly,41(3), 220-227. Retrieved May 05, 2017, from http://www.jstor.org/stable/10.2307/41241116?ref=search-gateway:a30408482b7d7 $613 \mathrm{~b} 002984$ c6ec 22953

[22] Oxford, R. L. (1997). Cooperative learning, collaborative learning, and interaction: Three communicative strands in the language classroom. The Modern Language Journal,81(4), 443-456. doi:10.1111/j.15404781.1997.tb05510.x

[23] Raina, R., \&Pande, N. (2012). Communication competence of Indian engineers in IT \&ITeS sector. Indian Journal of Industrial Relations, 47(3), 511-526.

[24] Salas, E., Wildman, J. L., \& Piccolo, R. F. (2009). Using simulation-based training to enhance management education. Academy of Management Learning \& Education,8(4), 559-573. doi:10.5465/ amle.2009.47785474 
[25] Schmidt, S. J. (2003). Active and cooperative learning using web-based simulations. The Journal of Economic Education,34(2), 151-167. doi:10.1080/00220480309595209

[26] Smutny, P., Prochazka, J., \&Vaculik, M. (2016). The relationship between managerial skills and managerial effectiveness in managerial simulation game. RevistaInnovar Journal Revista De CienciasAdministrativas Y Sociales,26(62), 11. doi:10.15446/innovar.v26n62.59385

[27] Suarez, S. L. (2005). Does English rule? Language instruction and economic strategies in Singapore, Ireland, and Puerto Rico. Comparative Politics,37(4), 459.doi:10.2307/20072904

[28] Wynter-Palmer, J. E. (2011). For high touch' service: An exploratory study on the use of incentives in Jamaica's hotel industry. Social and Economic Studies,60(2), 167-197.

[29] Yaffe, E. L., \& Rosario, I. F. (2009). Mandating English language proficiency for franchisees.

[30] Franchise Law Journal,28(3). Retrieved May 05, 2017, from http://www.jstor.org/stable/10.2307/ 29542239?ref =searchgateway:4500e4bb05e06977c285caae5637d78b

[31] Zeppel, H., \& Beaumont, N. (2012). Climate change and tourism futures: Responses by Australian tourism agencies: Responses by Australian tourism agencies. Tourism and Hospitality Research,12(2), 73-88. doi:10.1177/1467358412444807

[32] Zhu, Y. (2009). Managing business relationships in New Zealand and China: A semantic perspective. Management International Review,49(2), 225-248. doi:10.1007/s11575-008-0137-2.

\section{AUTHOR's BIOGRAPHY}

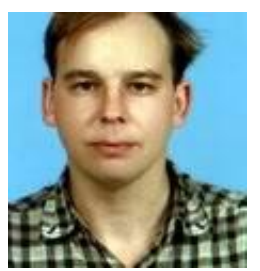

Andrew Szanajda is an Associate Professor at Overseas Chinese University, where he specializes in instructing writing as one way communication. He is the author of The Restoration of Justice in Postwar Hesse, 1945, Making Sense in History and Indirect Perpetrators: The Prosecution of Informers in Germany, 19451949, along with several journal articles in the disciplines of history, international relations, and ESL.

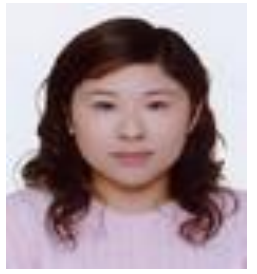

Fang-Chun Ou is an Assistant Professor at Overseas Chinese University, where she specializes in instructing TESL / TEFL Methodology, Educational Technology, Linguistics and Second Language Acquisition, Language Diagnosis \& Assessment, Reading Strategies, Business English, and Presentation Skills

Citation: Dr. Andrew Szanajda, Dr. Fang-Chun Ou. "A Simulation-Based Model for Teaching Business English: An Application in the Tourism and Hospitality Industries" International Journal on Studies in English Language and Literature (IJSELL), vol 6, no. 5, 2018, pp. 63-72. doi:http://dx.doi.org/10.20431/23473134.0605008 .

Copyright: (c) 2018 Authors. This is an open-access article distributed under the terms of the Creative Commons Attribution License, which permits unrestricted use, distribution, and reproduction in any medium, provided the original author and source are credited. 